\title{
Tribological Behaviour Comparison of ABS Polymer Manufactured Using Turning and 3D Printing
}

\author{
M. M. HANON ${ }^{1,2}$, M. KovÁCS, L. ZSIDAI ${ }^{3}$ \\ ${ }^{1}$ Szent István University, Mechanical Engineering Doctoral School, Institute for Mechanical Engineering \\ Technology, Sharba.Muammel.M.Hanon@phd.uni-szie.hu \\ ${ }^{2}$ Middle Technical University (MTU), Baquba Technical Institute, Baghdad, Iraq, muammel_mmr_85@yahoo.com \\ ${ }^{3}$ Szent István University, Institute for Mechanical Engineering Technology, zsidai.laszlo@gek.szie.hu
}

Abstract. Additive and subtractive manufacturing of Acrylonitrile Butadiene Styrene (ABS) were employed for fabricating samples. The Additive manufacturing was represented through $3 D$ printing, whereas subtractive manufacturing carried out by Turning. Some developments have been applied for enhancing the performance of the $3 D$ printer. Tribological measurements of the turned and 3D printed specimens have been achieved. Studying the difference between static and dynamic friction factors and the examination of wear values were included. $A$ comparison of the tribological behaviour of the turned and 3D printed ABS polymer has been investigated.

\section{Introduction}

There are many methods to fabricate a product depending on the material and the desired shape. Therefore, several theories were formed over the years. According to the most popular approach, three main groups are distinguished which are Subtractive manufacturing, additive manufacturing, and casting [1]. Through casting, the molten metal (material) is poured into a suitably formed cavity, i.e., mould. The shape of the solidified casting is determined by its mould. This procedure makes it difficult to create a suitable and unique mould for each piece [2]. Subtractive machining is a machining method whereby an unnecessary amount of material is separated from a starting block that necessarily has larger dimensions than the finished piece. Thus, with the help of a cutting tool, the excess material is dissipated as chips, while the desired geometry is revealed [3]. The most important methods of subtractive machining include (but not limited to) cutting, turning, engraving, milling, drilling, and grinding. Regarding the additive manufacturing, the finished piece is made up of layers of different materials that are stacked together. Nowadays, this form of machining is used by 3D printers. The most common types of raw materials are plastics, metals, papers, ceramics, and organic clays. The term rapid prototype manufacturing is increasingly replaced by 3D printing, which means a quick prototype manufacturing technology that is cheaper, simpler and more specific. Fast prototype manufacturing technology has many advantages comprise tool-free production, construction without assembly operations, complicated and complex geometries can be achieved as it is not costly, efficient process (few wastes, 95-98\% reusable), and it also allows home use [4]. 
Tribology is the science of friction, wear, and lubrication [5]. In another formulation, "Tribology is the science and technique of interacting and mutually moving surfaces, including related practical measurements. Friction takes place when two solid bodies move in opposite directions. So, if any two surfaces come in contact with each other, a phenomenon that prevents movement between surfaces occurs [6]. This phenomenon is a kind of friction. As the friction process happens, there is also a kind of oscillating movement. Where there is friction, wear will sooner or later appear. In this case, mechanical, thermal and chemical stresses cause material particles to break down from the moving surfaces to change the size and shape of the surface. Shape and size change means damage to the surface, which is structurally either compatible with the operation or exceeds the acceptable limit. Determining the size of wear is essential for running a friction mechanism since it is necessary to know the lifetime of the parts involved, and to avoid errors in the system by removing material. Wear is nothing more than the loss of material, which is typically characterized by the mass or volume of the release material [7].

By reading the literature, the rapidly evolving technology of 3D printing and the basics of tribology knowledge justify their interconnection in research. Knowing the material properties of new technologies is indispensable in designing the constructions, making it possible to produce a safe and low production waste product with greater success. 3D printers have undergone significant advances over the last 30 years and have become so widespread [8]. Table 1 shows a comparison of the most popular 3D printing technologies. It can be clearly seen that FDM (which is the most common technique of 3D printing at present) is inexpensive for the machine and its operation [9]. The disadvantage is the small workspace (about $200 \times 200 \times 200 \mathrm{~mm}$ ), but due to the small size of the most test pieces, it is entirely appropriate for a wide range of work. Commercially available ABS filament can be obtained at a relatively low cost, and this material is also used by industry for subtractive machining [10]. Therefore, it can be achieved valuable results for industry and ordinary users too.

In the present work, Tribological properties of ABS polymer were examined experimentally and compared in two methods of manufacturing, (i) additive manufacturing (3D printing), and (ii) subtractive manufacturing (turning). FDM has been chosen as the 3D printer for this study. Some steps for developing the FDM 3D printer have been carried out seeking more accuracy and ease of use. This printer used to produce the 3D printed samples which are employed in the tribology measures, to determine the tribological properties of the 3D printed parts where there is a lack in the literature about it.

\begin{tabular}{|c|c|c|c|c|c|c|}
\hline Printer / Considerations & SLA & LMD & FDM & 3DP & PolyJet & SLS \\
\hline Accuracy & 1 & 0 & 1 & 0 & - & 0 \\
\hline Printable size & O & $\mathbf{9}$ & 0 & 0 & 0 & O \\
\hline Postprocess & 1 & 0 & 1 & 0 & 9 & 1 \\
\hline Number of raw materials & 0 & O & $\mathbf{9}$ & 9 & 0 & 0 \\
\hline Machine size & 0 & 0 & 0 & 0 & 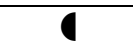 & O \\
\hline Price of the machine & 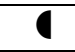 & $\mathrm{O}$ & 0 & $\mathrm{O}$ & $\mathrm{O}$ & $\mathrm{O}$ \\
\hline Price of operation & 0 & $\mathbf{6}$ & 0 & 0 & 0 & O \\
\hline
\end{tabular}

Table 1. Evaluating 3D Printers [9,11-13]. Note: Ogood; Imedium; Oweak 


\section{MATERIALS AND METHODS}

\subsection{D Printing}

The printed test specimens were made by a 3D printer works according to the Fused Filament Fabrication (FFF), which is the most common technology as mentioned in the literature. The model of the used 3D printer is K8200 (Figure 1). This printer consists of a frame structure, extruder, heated work surface, fan, adapter, power supply, filament holder, and controller. The G-Code of the 3D model can be incorporated directly from the SD card. All parameters and commands are given from a computer via USB cable. The specimen model was designed using Solid Edge software. The file has been saved as "stl" format due to it is compatible with most of the 3D printers slicing programs. For the slicing purpose, K8200 Repetier-Host software used which is the recommended and prepared for the same printer. The Technical specifications of 3D printer K8200 are listed in Table 2.

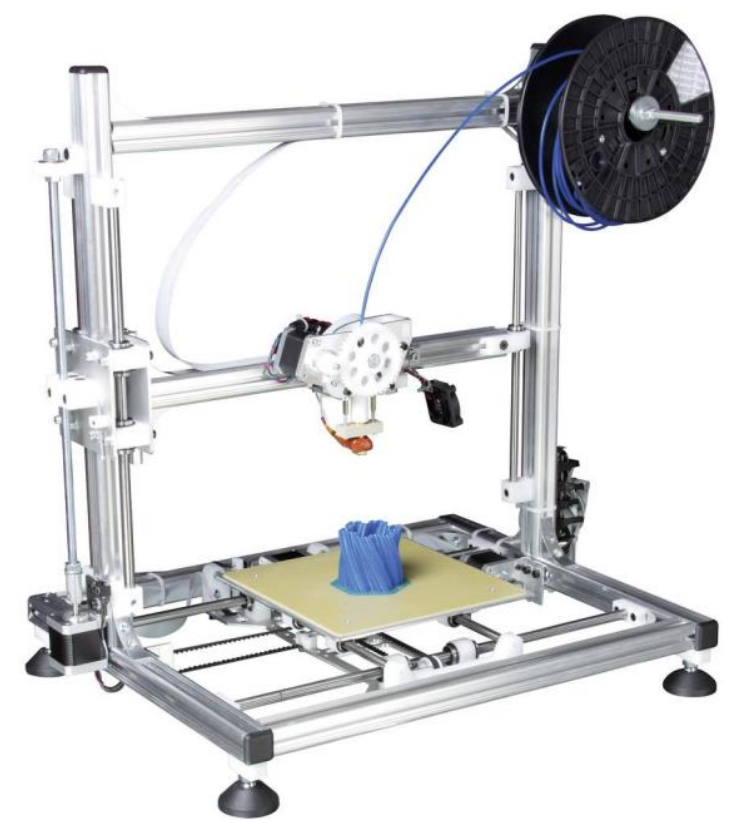

Figure 1. 3D printer K8200 [14].

\begin{tabular}{|l|l|}
\hline Technology: & FFF (Fused Filament Fabrication) \\
\hline Usable materials: & PLA and ABS \\
\hline Power supply: & $15 \mathrm{~V} / 6.6 \mathrm{~A}$ max \\
\hline port: & USB 2.0 and SD card \\
\hline Dimensions of printable area: & $200 \mathrm{x} 200 \mathrm{x} 200 \mathrm{~mm}$ \\
\hline Typical printing speeds: & $120 \mathrm{~mm} / \mathrm{s}$ \\
\hline Maximum print speed: & $150-300 \mathrm{~mm} / \mathrm{s}$ (depending on the object to be printed) \\
\hline Extrusion nozzle: & $0.5 \mathrm{~mm}$ \\
\hline Aluminium profiles: & $27.5 \times 27.5 \mathrm{~mm}$ \\
\hline Movement: & 3 stepping motor $(4 \mathrm{NEMA})$ \\
\hline Rated mechanical resolution: & $\mathrm{x}$ and y: $0.015 \mathrm{~mm}, \mathrm{z:} 0.781 \mu \mathrm{m}$ \\
\hline Nominal printing resolution: & Thickness (x, y): 0.5 mm, Layer thickness: $0.2-0.25 \mathrm{~mm}$ \\
\hline Dimensions: & Width: $500 \mathrm{~mm}$, Depth: $240 \mathrm{~mm}$, Height: $620 \mathrm{~mm}$ \\
\hline Weight: & $9 \mathrm{~kg}$ \\
\hline
\end{tabular}

Table 2. Technical specifications of K8200 printer [14]. 


\subsection{Development of 3D printer}

Several additional elements can also be purchased with the K8200 3D printer, to reduce the errors of the machine. For taking advantage of the machine, other items can also be created using the 3D printer itself. These additional purchased elements and the created ones are contributing to improving the printing by make it more accurate and convenient.

Regarding the current work, two extra elements have been bought from the manufacturer. The first one is an LCD panel with a built-in SD card reader (Figure 2 (a)). This allows the user to operate the printer independently, without requiring a permanent connection to the computer. The other is a temporarily connected glass covers the work surface, thus protecting the heating unit (Figure 2 (b)). This sheet merely is attached to the printer by means of documentary clamps for practical reasons since it is essential to remove and recapture the glass sheet for cleaning.

Another problem it must be dealt with is that the $x$-axes and $y$-axes are not strapping the belts in the ribbon belt drive. This could be solved by tensioning the y-axis, but not at the $x$-axis due to the mounting operations. Torsion spring was used for this purpose as shown in Figure 2 (c). The next development was to replace the M12 thread shaft of the z-axis with a trapezoidal thread shaft. After doing this, it is necessary to fine-tune the printer's z-axis parameters and to print new holders for the suspension (Figures 2 (d) and (e)). Print accuracy was increased after these changes, but there was still a problem during operation. The cooling of the printed component has been improperly implemented by the original fan, as most of the cooling capacity has not been utilized. Therefore, an air duct has been printed to overcome this problem. Thus, increasing the efficiency of cooling and making its distribution better (Figure 2 (f)). The last change is adjusting the zero point of the z-axis. For doing this, the first screwdriver was replaced by a micrometre, which ensures $0.01 \mathrm{~mm}$ adjustment (Figure 2 (g)). Figure 2 (h) shows the developed 3D printer after assembling all the additional items.

\subsection{Preparation of specimens}

\subsubsection{Turning specimens}

The ABS test specimens were prepared in the workshops of Szent István University using the industrial machining. Figure 3 shows the turning machine that used for the turned samples. The 3 -inch $7.5 \mathrm{~mm}$ diameter and $10 \mathrm{~mm}$ length specimens came out of the fundamental pieces. The material properties of the used ABS are shown in Table 3.

\begin{tabular}{|c|c|c|c|c|c|}
\hline \multicolumn{2}{|c|}{ General properties } & \multicolumn{2}{c|}{ Mechanical Properties } & \multicolumn{2}{c|}{ Thermal properties } \\
\hline Density & $1000-1200 \mathrm{~kg} / \mathrm{m}^{3}$ & Young's modulus & $1.1-2.9 \mathrm{GPa}$ & Melting temperature & - \\
\hline Price & $1.7-3.2 \mathrm{US} \$ / \mathrm{kg}$ & Hardness - Vickers & $5.6-15 \mathrm{HV}$ & Max. service temp. & $62-77^{\circ} \mathrm{C}$ \\
\hline & & Elastic limit & $19-51 \mathrm{MPa}$ & Thermal conductivity & $\begin{array}{c}0.19-0.34 \\
\mathrm{~W} / \mathrm{m} . \mathrm{K}\end{array}$ \\
\hline & & Tensile strength & $28-55 \mathrm{MPa}$ & Specific heat & $\begin{array}{c}1400-1900 \\
\mathrm{~J} / \mathrm{kg} . \mathrm{K}\end{array}$ \\
\hline & & Elongation & $1.5-100 \% \mathrm{MPa}$ & Thermal expansion & $\begin{array}{c}85-230 \mu- \\
\text { strain.K }\end{array}$ \\
\hline
\end{tabular}

Table 3. Material properties of ABS [15]. 
International Journal of Engineering and Management Sciences (IJEMS) Vol. 4. (2019). No. 1

DOI: 10.21791/IJEMS.2019.1.7.

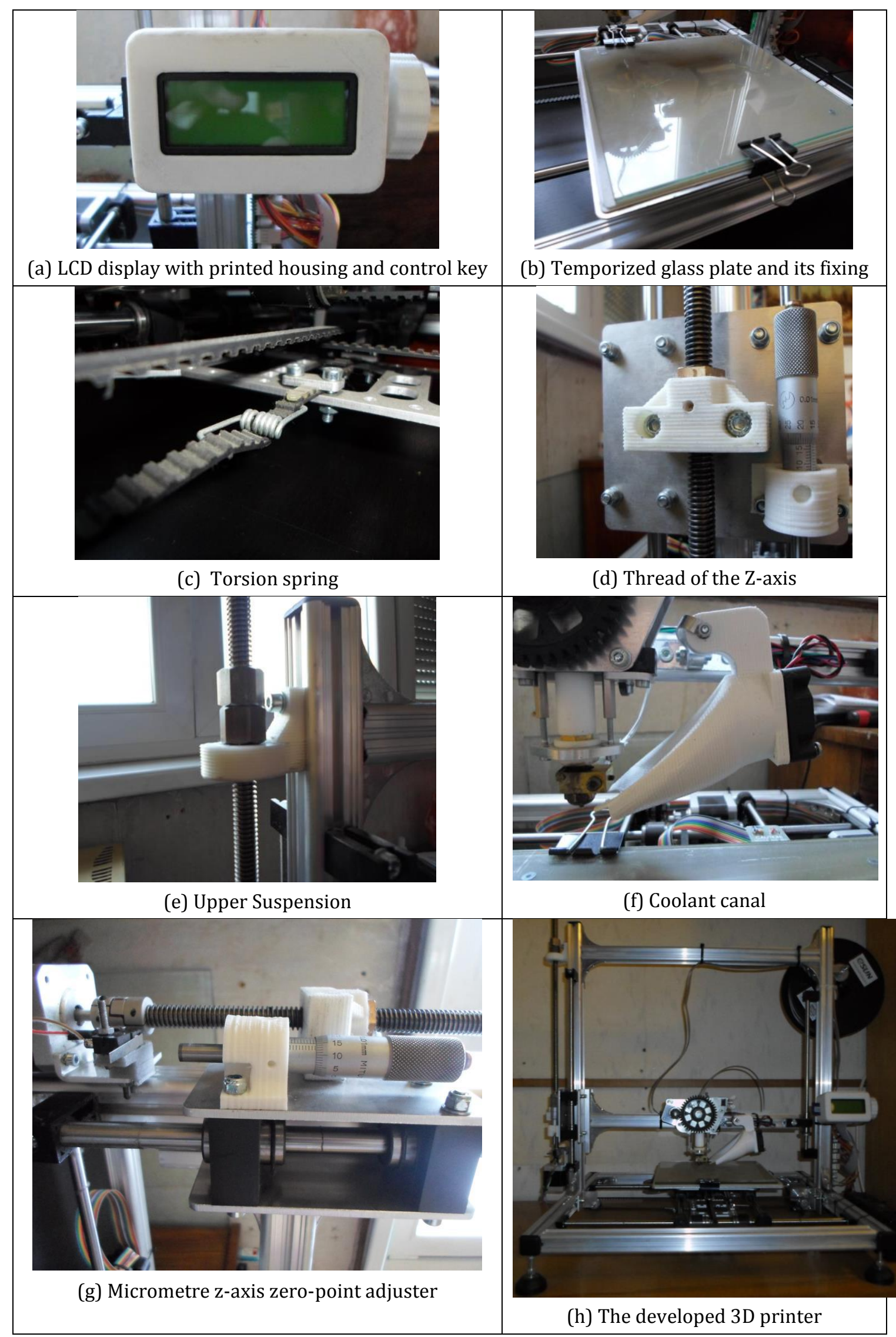

Figure 2. Developments of the 3D printer K8200. 


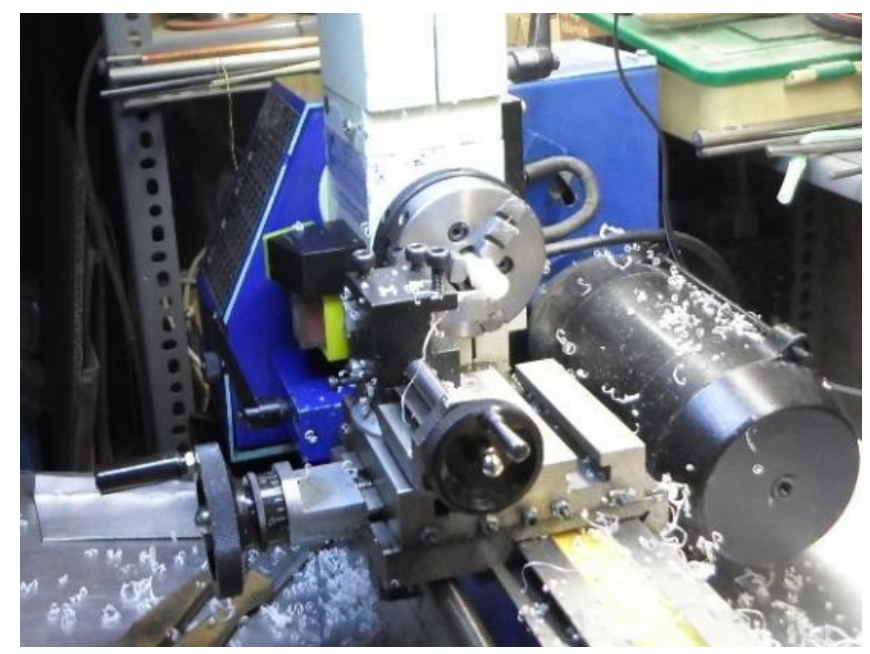

Figure 3. Turning ABS test piece.

\subsection{2. $3 D$ printing specimens}

The 3D printed test workpieces were made of ABS. It is available in the markets for printing made from a filament. Its key features are presented in Table 4 . The produced test specimens have a diameter of $7.5 \mathrm{~mm}$ and a length of $10 \mathrm{~mm}$ as seen in Figure 4.

\begin{tabular}{|c|c|c|}
\hline $\begin{array}{c}\text { Print } \\
\text { temperature }\end{array}$ & $\begin{array}{c}\text { First layer } \\
\text { temperature }\end{array}$ & $\begin{array}{c}\text { Heated work } \\
\text { surface }\end{array}$ \\
\hline $220-260^{\circ} \mathrm{C}$ & $235^{\circ} \mathrm{C}$ & Yes \\
\hline
\end{tabular}

Table 4. Main features of the used ABS filament [16].

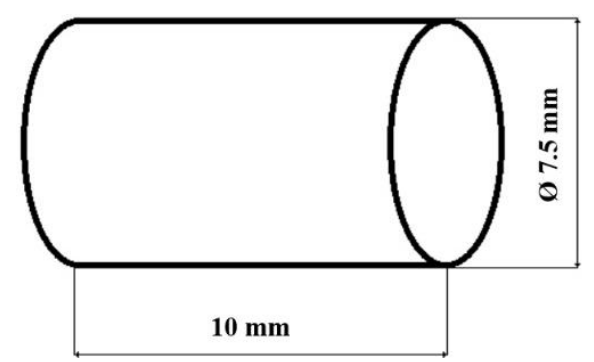

Figure 4. Dimensions of specimens.

The work table preheated approximately $60-70{ }^{\circ} \mathrm{C}$ for ABS Printing. It is treated for proper adhesion, due to $\mathrm{ABS}$ is more delicate for temperature fluctuations than some other polymers during printing. In case of insufficient cooling during printing, no optimum melting of the layers is reached, and brittle fracture of material takes place. Samples of the specimens that produced by turning and 3D printing of ABS polymer are shown in Figure 5.

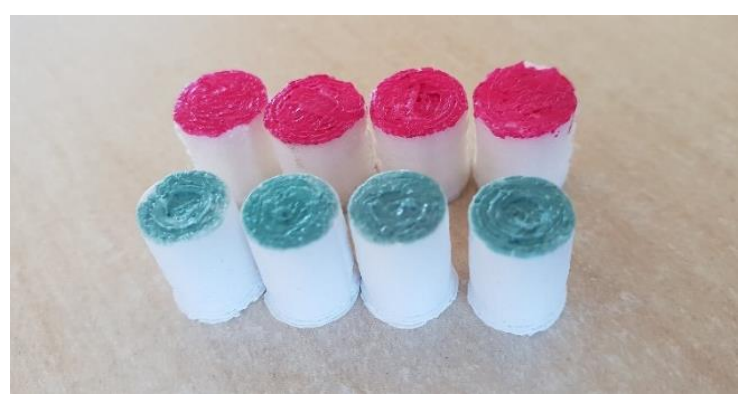

Figure 5. Turning and 3D printing test specimens. 


\subsection{Measurements}

After printing the specimens, the measurements were performed at tribology test room in Szent István University under the laboratory conditions. The first step in the measurement process is to connect the measuring circuit, which consists of a computer, Spider 8 measuring converter, a tribotester and, an inverter. The indispensable part of the measuring system is the tribotester, which is in this case compatible with polymers. Figure 6 shows the structure of the used PLINT TE 77 tribotester (High-Frequency Tribotest), employed by Dr László Zsidai for previous research.

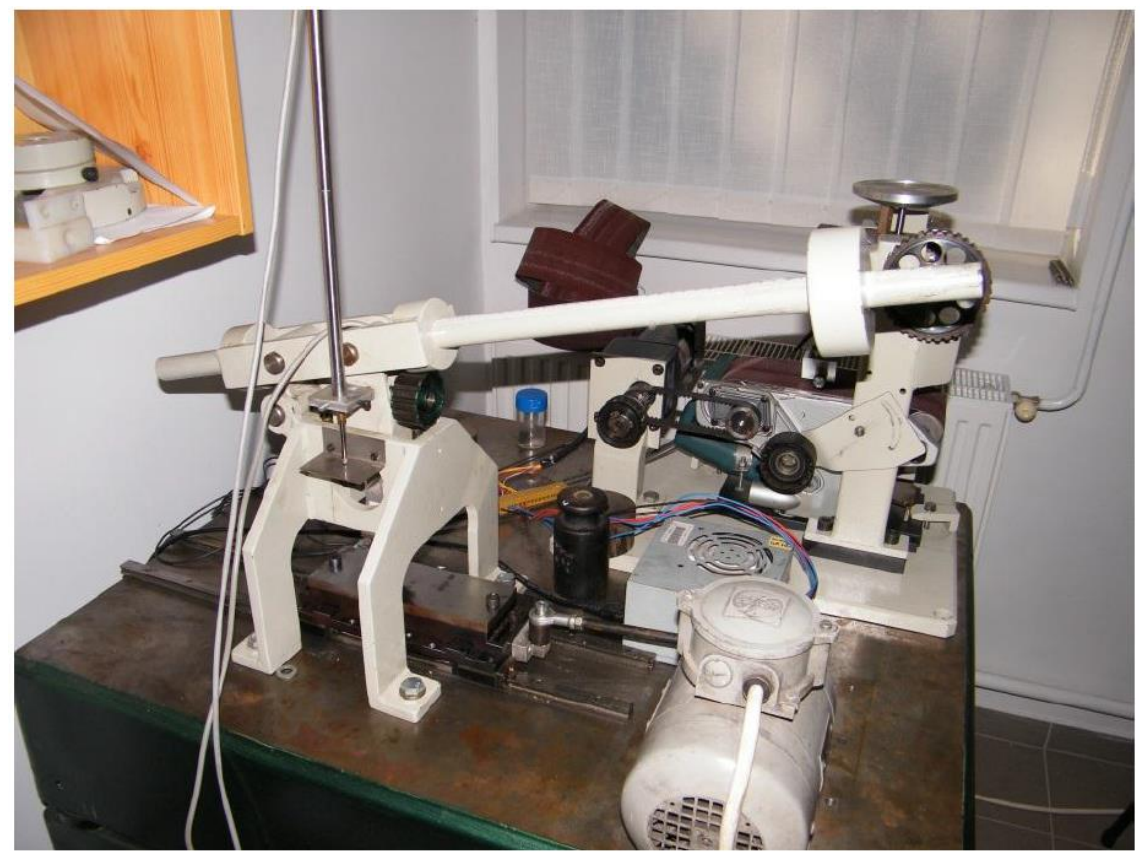

Figure 6. Tribotester.

The alternating movement required for the measurement is provided by a variable speed electric motor with an adjustable frequency drive and an eccentric disc. This is coupled with an interchangeable push rod by the sliding plate on the linear guides. The frequency inverter can be used to set the measurement frequency to the desired value accurately. With the eccentricity of the thrust bar, the stroke length can be adjusted according to the measurement parameters. During the current measurement, the test specimen is subjected to a static load. The loading force can be adjusted by selecting and positioning the load weights on the load arm. Various sensors in the measuring system are required to measure the friction force and other essential features. Hence, the system can measure static force, friction force, compression force along 2 coordinates, displacement along 3 coordinates, and ambient temperature. Clamping heads were used for fixing the specimen. The parallel clamping jaws should be clamped by two screws provided. The clamping feature is characterized by a small movement that allows parallel rotation of the shaft to ensure the self-alignment of the body during the test. Thus, the specimen is equally laid on the steel counterpart, avoiding the possibility of wear and misalignment and minimizing the probability of inaccurate measurement. Before starting the measurement, a number of parameters must be defined which are given in Table 5 . The examinations were carried out under constant environmental conditions. Based on previous measurements, the duration and load of the measurements were executed. These parameters were suitable for determining the goals of the current work. 
DOI: 10.21791/IJEMS.2019.1.7.

\begin{tabular}{|c|c|}
\hline Surface roughness of steel counterpart, $[\mathbf{\mu m}]$ & 3.2 \\
\hline Test duration, $\mathbf{t}[\mathbf{s}]$ & 130 \\
\hline Load, $\mathbf{F}[\mathbf{N}]$ & 180 \\
\hline Alternating motion frequency, $\mathbf{f}[\mathbf{H z}]$ & 10 \\
\hline Average speed, $\mathbf{v}[\mathbf{m} / \mathbf{s}]$ & 0.05 \\
\hline Stroke length, $[\mathbf{m m}]$ & 15 \\
\hline Relative humidity, $\mathbf{R h}[\mathbf{0}]$ & 50 \\
\hline
\end{tabular}

Table 5. Tribology measurement parameters.

\section{RESULTS AND DISCUSSION}

The friction force was determined per cycle and represented by the sliding distance. This makes the formed curve is very dense. Hence, it is not suitable for extracting remarkable data. Therefore, it was better to pick two short areas of the whole sliding distance to grasp the attitude of the coefficient of friction. The front and end cycles were selected for this purpose. Two values from the curve between each inflexion point were extracted, the maximum value and an average of the steady state. These values resulting show the static and dynamic friction coefficients respectively as a function of the displacement path. During the test, both static and dynamic friction factors were evaluated. The value of static friction factors is always higher than the relative dynamics. Wear rate measurements have been done for the ABS samples which are manufactured by turning, and 3D printing as well. The following sections clarify the procedure and the measurements mentioned above.

\subsection{ABS test result of turning}

It can be seen in Figure 7 that after the initial fluctuation, the coefficient of friction is set to a value. Its static movement trends are followed closely by the value of the dynamic factor throughout the measurement time. Typically, there is a value taken by both curves named difference. This is clearly visible on the green curve. The curve was similar to all the measurements of the tested samples, with no remarkable sound effects. In Figures 8 (a \& b) several cycles have been magnified from the beginning and the end of the sliding distance. Figure 9 shows the wear rate of the specimens in $\mathrm{mm}$ in relation to the thread length.

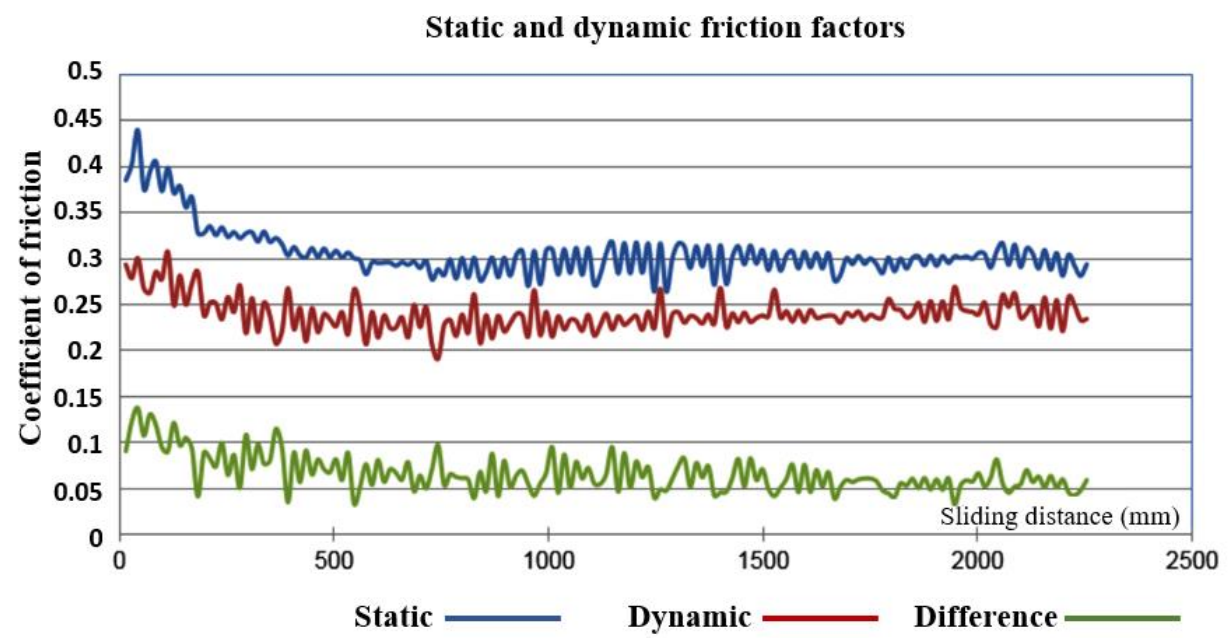

Figure 7. Friction factors of the turned specimens. 


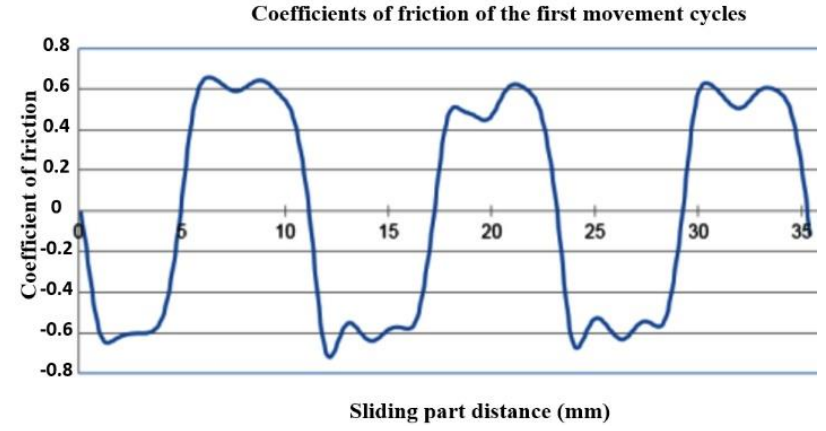

(a)

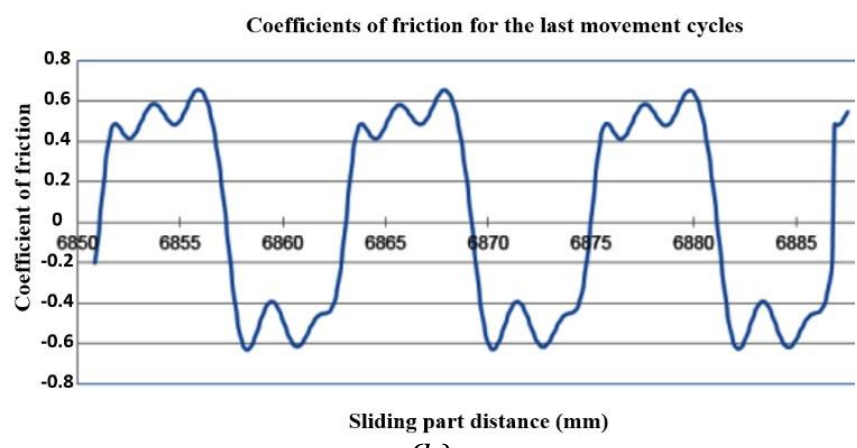

(b)

Figure 8. Magnified cycles of (a) movement beginning, and (b) end movement.

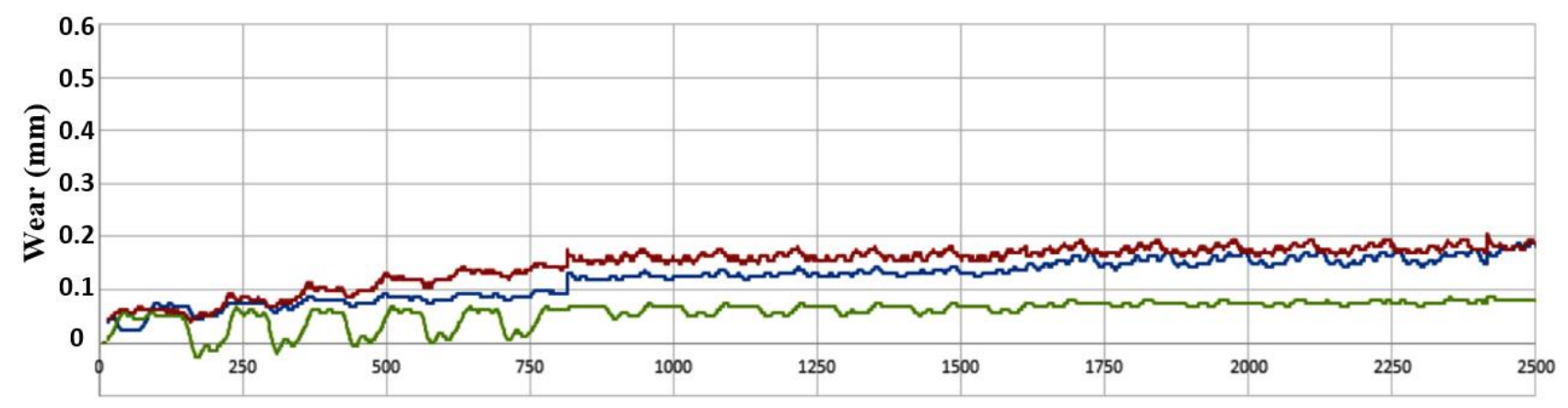

Sliding distance (mm)

Figure 9. The wear curves of the three repeated tests of turned ABS.

\subsection{ABS test result of $3 \mathrm{~d}$ printing}

Basically, the same can be said about the evaluated diagram as in the case of the turning specimens. However, it can be seen in Figure 10 that the static and the dynamic curves do not typically coincide. From the difference curve, the value between the two curves is almost constant. There was no distinctive sound effect here during the measurement. The measurement curve does not show any significant difference during the measuring time (Figures 11 a \& b). The wear rate of the 3D printed specimens is illustrated in Figure 12.

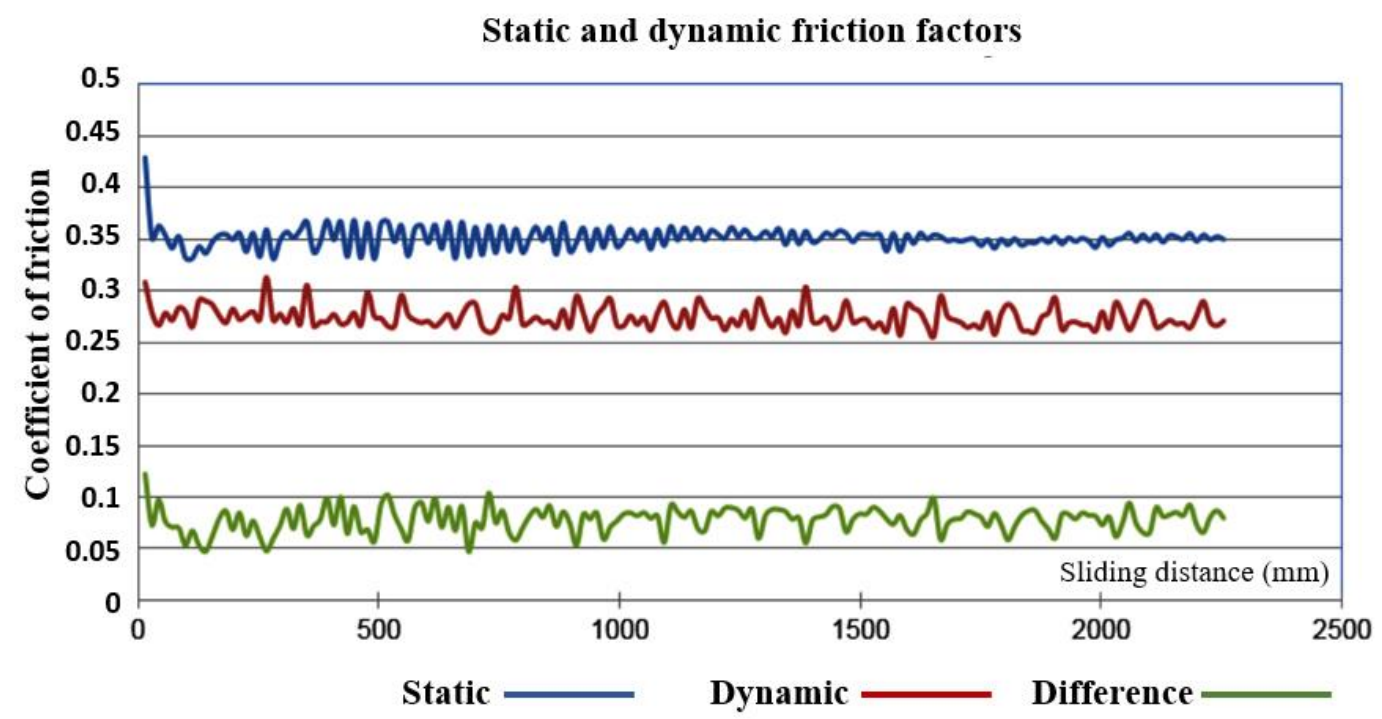

Figure 10. Friction factors of the $3 D$ printed specimens. 


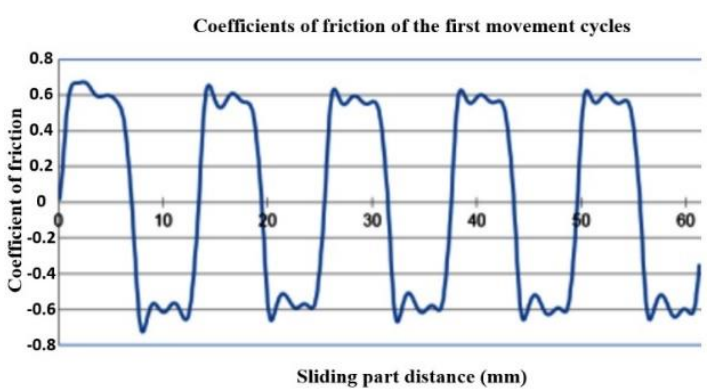

(a)

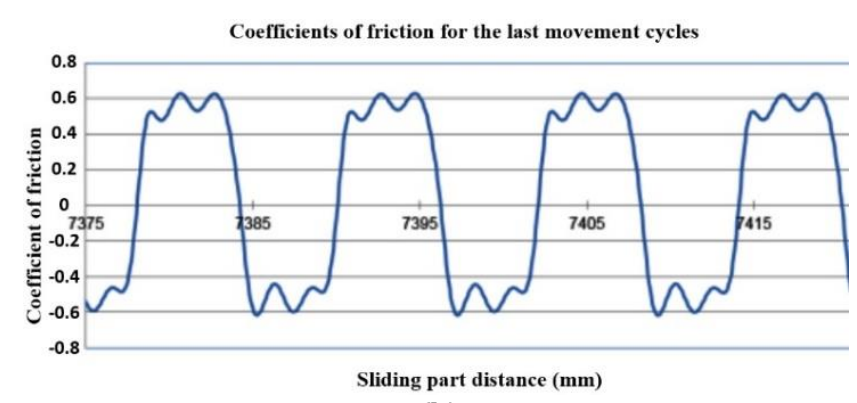

(b)

Figure 11. Magnified cycles of (a) movement beginning, and (b) end movement.

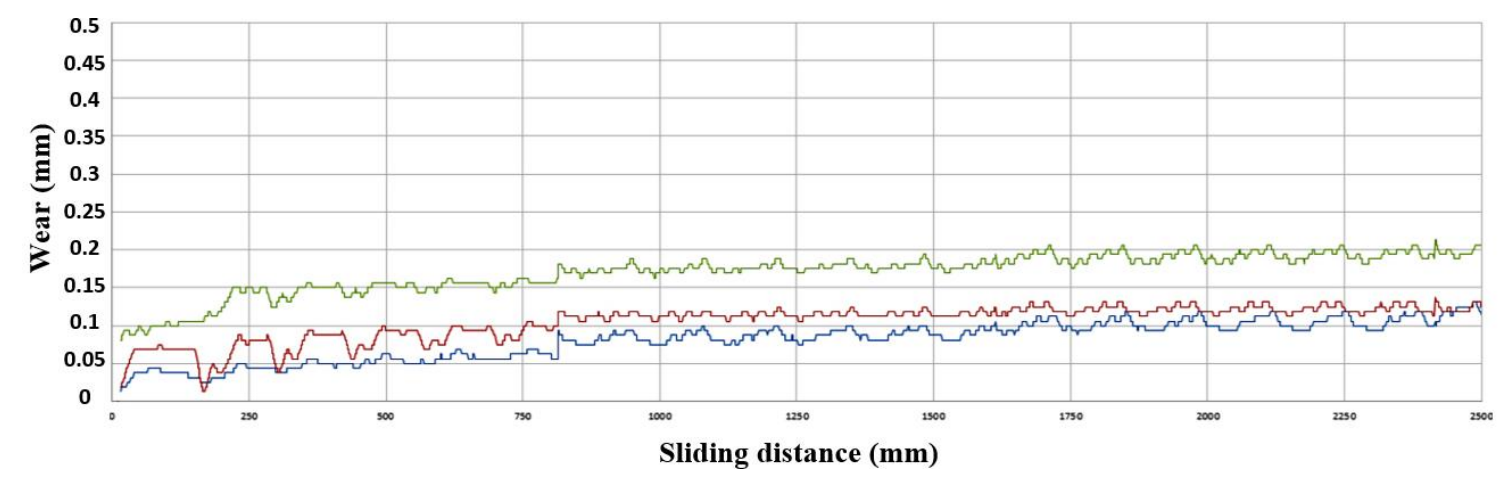

Figure 12. The wear curves of the three repeated tests of $3 D$ printed ABS.

\subsection{Comparison of results and discussion}

Figure 13 shows the maximum and most frequently used value of the dynamic friction coefficient. The blue column indicates the friction coefficient of the stabilized state, while the maximum friction value during the measurement period is indicated by the red supplementary column. The values shown here are from the average of multiple measurements. From the diagram, it is clear that the ABS-based specimens are in the same range of dynamic friction coefficient regardless of the machining method. But the turned ABS is slightly higher, which means more instability in its friction behaviour. In Figure 14 , the average wear values of the individual specimens during the measurement were compared. Values for y-axis are in millimetres. It can be seen that the wear levels of the 3D printed ABS is somewhat lower than the turned ABS. This suggests that at the beginning of the test, the adhesion wear mechanisms in the turning machined surface (smoother) are stronger than the printed surface (rougher), although the surface pressure of the printed is smaller than the turned.

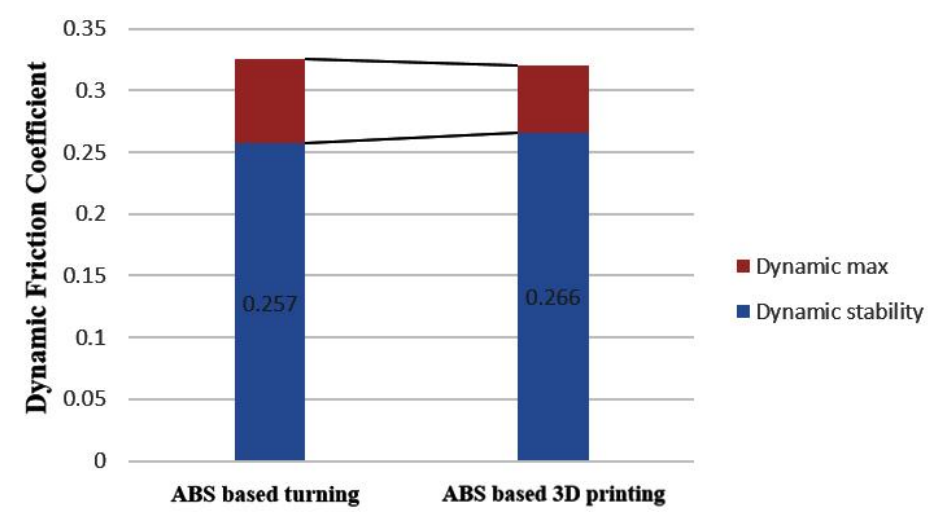

Figure 13. measurement data of the dynamic friction coefficient. 


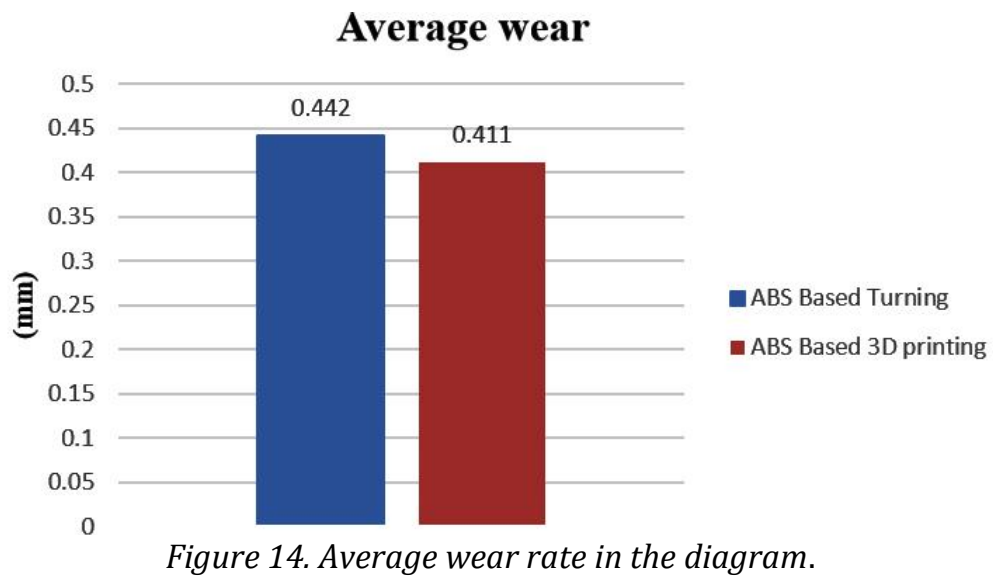

\section{Conclusion}

The frictional properties of 3D printed ABS filaments and the industrial fabricated of the same material were obtained. The determination of the difference between static and dynamic friction factors and the examination of wear values were included. In view of these findings, it can be concluded a statement on the effect of the manufacturing technologies on the tribological behaviour. Based on the alternating-motion experiments carried out on the pair of cylindrical plastic flat plate used in this investigation, the following can be determined: The alternating-motion system used during this research allows the measuring of the difference between static and dynamic friction factors and wear curves, so it is suitable for comparative tests of this type. The obtained tribological properties of the 3D printing and turning specimens of the same ABS material showed minor differences have occurred. Therefore, the research in this area would be worthwhile if it can be extended to other polymers in the future with various colour of materials and different tribosystems.

\section{Acknowledgement}

This work was supported by the Stipendium Hungaricum Programme and by the Mechanical Engineering Doctoral School, Szent István University, Gödöllő, Hungary.

\section{References}

[1] S. Kalpakjian - S. R. Schmid - H. Musa (2009) Manufacturing Engineering and Technology. 6th ed., Pearson Publications, Singapore.

[2] B. Ravi (2005) Metal Casting: Computer-Aided Design and Analysis. PHI Learning Pvt. Ltd.

[3] H. Paris - H. Mokhtarian - E. Coatanéa - M. Museau - I. F. Ituarte (2016) Comparative environmental impacts of additive and subtractive manufacturing technologies. CIRP Annals, 65(1) pp. 29-32.

[4] S. H. Huang - P. Liu - A. Mokasdar - L. Hou (2013) Additive manufacturing and its societal impact: a literature review. The International Journal of Advanced Manufacturing Technology, 67(5-8) pp. 1191-1203.

[5] U. Nirmal - J. Hashim - M. M. H. Megat Ahmad (2015) A review on tribological performance of natural fibre polymeric composites. Tribology International, 83 pp. 77-104. 
[6] L. Zsidai - P. De Baets - P. Samyn - G. Kalacska - A. P. Van Peteghem - F. Van Parys (2002) The tribological behaviour of engineering plastics during sliding friction investigated with small-scale specimens. Wear, 253(5-6) pp. 673-688.

[7] N. K. Myshkin - M. I. Petrokovets - A. V. Kovalev (2005) Tribology of polymers: Adhesion, friction, wear, and mass-transfer. Tribology International, 38(11-12) pp. 910-921.

[8] M. Attaran (2017) The rise of 3-D printing: The advantages of additive manufacturing over traditional manufacturing. Business Horizons, 60(5) pp. 677-688.

[9] P. Parandoush - D. Lin (2017) A review on additive manufacturing of polymer-fiber composites. Composite Structures, 182 pp. 36-53.

[10] P. Tran - T. D. Ngo - A. Ghazlan - D. Hui (2017) Bimaterial 3D printing and numerical analysis of bio-inspired composite structures under in-plane and transverse loadings. Composites Part B: Engineering, 108 pp. 210-223.

[11] M. Srinivas - B. S. Babu (2017) A Critical Review on Recent Research Methodologies in Additive Manufacturing. Materials Today: Proceedings, 4(8) pp. 9049-9059.

[12] T. D. Ngo - A. Kashani - G. Imbalzano - K. T. Q. Nguyen - D. Hui (2018) Additive manufacturing (3D printing): A review of materials, methods, applications and challenges. Composites Part B: Engineering, 143 pp. 172-196.

[13] J. W. Stansbury - M. J. Idacavage (2016) 3D printing with polymers: Challenges among expanding options and opportunities. Dental Materials, 32(1) pp. 54-64.

[14] N. V. Velleman (Accessed: 07-Aug-2018) 3D Printer K8200. [Online]. Available: http://www.k8200.eu/specs/.

[15] M. F. Ashby (2011) Materials Selection in Mechanical Design. Elsevier.

[16] S. E. I. C. L. Esun (Accessed: 15-Sep-2018) esun 3D filament ABS white. [Online]. Available: http://www.esun3d.net/products/103.html. 